\title{
DIVISÃO DO TRABALHO E CRISE DA UNIVERSIDADE
}

\author{
Artur Bispo dos Santos Neto ${ }^{1}$
}

\begin{abstract}
Resumo:
O presente artigo tem como propósito abordar a educação como um complexo que envolve a totalidade da existência humana e está relacionada ao modo como os homens organizam a reprodução de sua existência material pela mediação da divisão social do trabalho. Nele se ressalta como a universidade pública se articula à divisão social do trabalho no modo de produção capitalista e, ainda, como amolda às proposições e determinações do mercado - tanto no estágio de expansão capitalista no Brasil quanto na quadra histórica de crise estrutural do capital, quando a educação se consubstancia na forma de mercadoria pela mediação das contrarreformas fragmentadas experimentadas no âmbito da educação superior e da consistente implementação de novas modalidades de práticas educativas.
\end{abstract}

Palavras-chave: Universidade, Divisão do trabalho, Mercadoria

\begin{abstract}
:
The present paper proposes to broach the education as a complex that involves the totality of the human's existence and it is related to the way as men organize the reproduction of their material existence by the mediation of the social work division. In this paper is emphasized how the public university articulates itself to the social work division in the capitalist production way and, still, how mold itself to the propositions and determinations of market - as much in the stage of capitalist expansion in Brazil as in the historical occasion of the capital structural crisis, when the education consubstantiates itself in the form of goods by the mediation of fragmented counter reformations experienced within the compass of higher education and the consistent implementation of new modalities of educational practices.
\end{abstract}

Keywords: University, Work division, Goods.

\section{Introdução}

A aprendizagem é uma coisa oniabrangente e penetra nas diferentes camadas da existência humana - tanto na epiderme da vida imediata quanto nas camadas mais profundas da existência mediata, tanto na esfera fenomênica quanto no reino substancial da essencialidade. Nesse aspecto, merece destaque que a educação precede a existência da escola propriamente dita, já que durante muito tempo os homens desenvolveram

\footnotetext{
${ }^{1}$ Professor Adjunto do Curso de Filosofia da Universidade Federal de Alagoas (UFAL). Doutor em Letras e Linguistica pela UFAL. Colaborador do Programa de Pósgraduação em Serviço Social da UFAL.
} 
processos pedagógicos sem ter consciência disso e sem a institucionalização de uma entidade para atender a esses propósitos. Isso porque a atividade da educação consistia numa tarefa de toda a sociedade e não numa atividade específica de uma determinada classe de homens como mestres ou professores.

É importante destacar que a institucionalização da educação não se processou de uma vez na história, mas se inscreveu lentamente, e que está relacionada diretamente ao desenvolvimento da divisão do trabalho. Em A ideologia alemã, Marx e Engels (1987) entendem a divisão do trabalho como uma categoria que perpassa todas as formas de sociedade, encontrando nas sociedades de classes distintas formas de manifestação. A divisão do trabalho é uma universalidade que se manifesta de maneira específica em cada sociedade. Nesse aspecto, é uma categoria essencialmente articulada às determinações objetivas, ao modo como os homens organizam a sua existência material e espiritual. Ao desenvolverem a produção de sua existência material, os homens constituem também os produtos de sua consciência e de sua educação.

A primeira divisão é essencialmente natural, pois é regida pelas disposições e habilidades naturais, fundada na distinção existente entre os sexos e as faixas etárias. Essa divisão é própria da fase história em que predomina no ser social o mutismo natural. Na comunidade tribal, a divisão do trabalho "está ainda pouco desenvolvida e se limita a uma maior extensão da divisão natural no seio da família" (MARXENGELS, 1987, p. 30). A divisão, nesse caso, emana da necessidade de ampliar a produção para atender as carências resultantes do aumento demográfico e do aprimoramento das condições de existência.

$\mathrm{Na}$ propriedade antiga, a divisão do trabalho “já é mais desenvolvida. Encontramos já a oposição entre a cidade e o campo, e mais tarde a oposição entre os Estados que representam o interesse das cidades e os que representam o interesse das cidades e os que representam os interesses do campo" (MARX-ENGELS, 1987, p. 31). O surgimento da cidade impõe o desenvolvimento duma estrutura organizacional mais complexa que a existente no universo agrário, quer dizer, ela pressupõe a constituição de complexos mais sofisticados como a educação, o direito, o sistema de tributos, o corpo coercitivo do Estado etc. A cidade acaba impondo a concentração populacional, a concentração dos instrumentos de produção, dos instrumentos de diversão e do capital; diferentemente do campo, que permanece perpassado pelo isolamento e pela fragmentação.

\begin{tabular}{|l|l|l|l|l|}
\hline Qevista Dialectus & Ano 1 & n. 1 & Julho-Dezembro 2012 & p. 87-100 \\
\hline
\end{tabular}


O nível de desenvolvimento educacional de uma sociedade pode ser mensurado pelo desenvolvimento alcançado pela divisão do trabalho, em que seu desenvolvimento está plenamente conectado ao desenvolvimento das forças produtivas. A divisão do trabalho conduz à separação entre campo e cidade, trabalho agrícola e trabalho urbano, trabalho na indústria e trabalho no comércio. Ela, por sua vez, processa-se numa série ininterruptas de subdivisões entre os indivíduos que cooperam nos distintos trabalhos. Essas subdivisões são determinadas pelo modo como o trabalho comparece nas diferentes formas de sociedade (patriarcalismo, escravidão, capitalismo, comunismo). Segundo Marx e Engels (1987, p. 29): “As diversas fases de desenvolvimento da divisão do trabalho representam outras tantas formas diferentes da propriedade: ou, em outras palavras, cada nova fase da divisão do trabalho determina igualmente as relações dos indivíduos entre si, no que se refere ao material, ao instrumento e ao produto do trabalho".

A separação entre cidade e campo potencializa a separação entre trabalho material e trabalho intelectual. É somente com a divisão entre trabalho intelectual e trabalho manual que realmente se constitui a divisão social do trabalho (MARXENGELS, 1987). Apesar dos intelectuais antigos conceberem sua atividade intelectiva como trabalho (improdutivo). No entanto, é somente como o desenvolvimento das condições objetivas que emergem as possibilidades para eles possam dedicar-se exclusivamente as atividades espirituais. É assim que surge a teologia, a filosofia, a educação. É nessa época que a consciência "pode realmente imaginar ser algo diferente da consciência da práxis existente, representar realmente algo sem representar algo real" (MARX-ENGELS, 1987, p. 45).

A divisão do trabalho admite a possibilidade da consciência ou as relações existentes entrar em contradição com as forças de produção existentes. Marx e Engels acrescentam ainda que as forças produtivas, a consciência e o estado social podem entrar em contradição entre si, porque, "com a divisão do trabalho, fica dada a possibilidade, ainda mais, a realidade, de que a atividade espiritual e a material - a fruição e o trabalho, a produção e o consumo - caibam a indivíduos diferentes; e a possibilidade de não entrarem esses elementos em contradição reside unicamente no fato de que a divisão do trabalho seja novamente superada" (1987, p. 45-46).

Nas sociedades de classe, a divisão do trabalho e a propriedade privada são termos unívocos. Ela emerge na divisão natural do trabalho e ganha contornos mais sofisticados na divisão social do trabalho. E a sociedade capitalista intensifica de tal

\begin{tabular}{|l|l|l|l|l|}
\hline Qevista Dialectus & Ano 1 & n. 1 & Julho-Dezembro 2012 & p. 87-100 \\
\hline
\end{tabular}


maneira essa contradição que se perde completamente a relação existente entre a atividade laboral e atividade intelectiva, e o trabalhador comparece como uma mônada completamente cindida em relação ao processo de controle e determinação da atividade produtiva. A divisão social acaba se manifestando de forma tão aviltante e dominadora que culmina naturalizando a atividade especializada do operário.

\section{Divisão social do trabalho e educação}

Uma observação preliminar sobre a educação permite notar que sua difusão está prioritariamente relacionada às necessidades da constituição de complexos ideológicos fundamentais ao processo de dominação de determinada classe social sobre as demais classes através da intensificação da divisão social do trabalho. Como essa dominação não pode ser fixada sobre bases tão somente coercitivas, é preciso que os valores das classes dominantes se constituam como os valores dominantes de toda a sociedade, por isso a educação - bem como as mediações de segunda ordem, como a política, a moral, o direito, a religião etc. - deve servir para legitimar a expropriação do tempo de trabalho excedente produzido pela classe realmente produtiva.

Apesar do caráter eminentemente interessado de todo processo educativo, é interessante destacar que existiram períodos na história da humanidade (Grécia antiga, Renascença ${ }^{2}$ e Iluminismo) em que as classes dominantes foram capazes de superar a idiossincrasia duma proposta duma pedagógica meramente contingente e particular, para postular a necessidade da formação (Bildung) humana em seu sentido mais amplo. No estágio histórico que precede a Revolução Francesa, por exemplo, verifica-se que os teóricos da burguesia colocaram na ordem do dia a relevância da educação do homem integral. Isso pode ser observado nos escritos de Jean-Jacques Rousseau, Immanuel Kant, F. Schiller, Goethe etc. No entanto, a intensificação da divisão social do trabalho deixou para trás essas pretensões iluministas, a educação do homem na perspectiva da humanidade, para colocar na ordem do dia a necessidade da educação centrada na disjunção monumental entre trabalho manual e trabalho intelectual. Além disso, o

\footnotetext{
2 Os representantes da Renascença destacam-se para peculiar capacidade de tratar de várias questões; isso era possível porque não tinham sidos contaminados ainda pela divisão social do trabalho, que perpassaria toda a sociedade capitalista. Eles conseguiam desenvolver várias habilidades porque não eram simplesmente artistas, mas tanto artistas como filósofos, matemáticos, geômetras, físicos etc. Escreve Engels: "Os homens que fundaram a moderna denominação burguesa foram tudo, pelo menos burgueses limitados. Os heróis daquele tempo, na realidade, ainda não haviam sido esmagados pela divisão social do trabalho, cujos efeitos mutiladores, que tornam o homem unilateral, sentimos tão frequentemente nos seus sucessores" (apud LUKÁCS, 1965, p. 23).
}

\begin{tabular}{|l|l|l|l|l|}
\hline Qevista Dialectus & Ano 1 & n. 1 & Julho-Dezembro 2012 & p. 87-100 \\
\hline
\end{tabular}


desenvolvimento progressivo da divisão social do trabalho traz em seu bojo a intermitente predominância da relação econômica fundada no valor ${ }^{3}$, que torna os seres humanos meros artefatos da lógica da produção de mercadorias.

O ethos capitalista é perpassado pela necessidade da formação do indivíduo segundo os imperativos do mercado e não na perspectiva episódica da educação integral dos educadores gregos, dos renascentistas e dos filósofos iluministas. Assim, os pensadores da adolescência do capitalismo foram condenados a circunscrever suas proposições pedagógicas ao reino das utopias irrealizáveis, como alude Mészáros:

Eles não podiam equiparar-se sob nenhum aspecto à realidade prosaica das forças que impuseram com sucesso a todo custo o imperativo auto-expansivo fundamentalmente destrutivo do capital. Pois a tendência socioeconômica da alienação que tudo traga foi suficientemente poderosa para extinguir, sem deixar rastro, até mesmo os ideais mais nobres da época do Iluminismo (2007, p. 294).

É incontestável o fracasso das propostas educacionais de reformar a estrutura da sociedade através da mudança tão somente dos indivíduos isolados, pois todas as premissas pedagógicas burguesas acabaram sempre por se adaptar às determinações reprodutivas fundamentais à reprodução do sistema do capital, mesmo aquelas que se apresentaram na época histórica em que a burguesia possuía alguma espécie de interesse em vaticinar suas propostas como envolventes de toda a humanidade e não apenas de seus interesses particulares. Isso porque na contabilidade capitalista o indivíduo apenas pode emergir como força de trabalho e não como ser humano verdadeiro e omnilateral. É preciso lembrar que as instituições formais da educação, como a universidade, são apenas uma modalidade do sistema global de internalização dos valores do capital, e essa modalidade de educação é incapaz de conduzir a humanidade à emancipação, pois tem como princípio peculiar atender as determinações impostas pela divisão social do trabalho estabelecida.

A necessidade de reestruturar o processo de produção de acordo com os novos padrões de acumulação e expansão conduziu o capital ao aperfeiçoamento de seus instrumentos pedagógicos. Nesse processo, a educação formal não passou de mera criada de quarto da difusão da ideologia necessária à consolidação da divisão do trabalho, e a formatação desse sistema hierarquizado recorre à educação para difundir a ideologia da ascensão social em que os filhos da classe trabalhadora são educados

\footnotetext{
${ }^{3} \mathrm{O}$ caráter claramente social do valor - na medida em que emerge da relação fundamental entre valor de uso e valor de troca, em que o valor de troca determina o valor de uso - não pode deixar de obliterar sua essencialidade refrataria e fetichizadora, e as relações entre os homens acabam se consubstanciando como relação entre coisas (MARX, 1985).
}

\begin{tabular}{|l|l|l|l|l|}
\hline Qevista Dialectus & Ano 1 & n. 1 & Julho-Dezembro 2012 & p. 87-100 \\
\hline
\end{tabular}


segundo os preceitos da mobilidade social. É preciso destacar que no modo de produção capitalista apenas os indivíduos "podem ser integrados em uma estrutura vigente da sociedade que é constituída pelas próprias classes" (MÉSZÁROS, 2008, p. 68). Os indivíduos podem passar de uma classe à outra, mas as classes e seus antagonismos se constituem como plataforma estrutural do modo de ser do capital, que apenas pode se reproduzir exercendo controle absoluto sobre o trabalho. Assim, não é possível espécie alguma de conversão mágica da classe proletária à condição de classe burguesa, como vaticinam os ideólogos do capital.

\section{Educação superior como mercadoria}

A revolução burguesa brasileira (1930), instaurada segundo o modelo prussiano, representou a constituição de uma perspectiva pedagógica orientada pelos interesses de reprodução da dominação imperialista numa região que sempre se manteve no âmbito internacional como espaço de colonização do capital (MINTO, 2011). Essa revolução não passou de rearranjo das classes dominantes, em que parte do capital é deslocada da produção agrícola para a produção industrial. É uma revolução que não representa nenhuma alteração substancial das estruturas de controle e comando das decisões efetivas $^{4}$. O processo de industrialização é instaurado em plena consonância com as determinações do capital, que pressupõe, no contexto de guerra mundial, o estabelecimento de novas bases subjetivas e objetivas para o desenvolvimento das economias dependentes. É nesse horizonte que se inscreve a gênese da universidade brasileira.

A universidade surge para atender a uma dupla carência: de um lado, a necessidade de preparação e formação dos filhos das classes dominantes para os novos desafios da administração racional e consistente do capital; do outro, a exigência de formação da mão de obra segundo os imperativos de comando do capital sobre o trabalho. De forma geral e abrangente, a universidade se constitui como mediação fundamental da subordinação da nascente classe operária aos preceitos de controle da burguesia nacional e internacional, constituindo-se como imperativo fundamental do

\footnotetext{
${ }^{4}$ O governo populista de Vargas representou a constituição de um cenário político marcado pela tentativa de substituição das importações. Para isso punha-se como imprescindível a construção das indústrias de base como metalurgia, siderurgia, petróleo etc. O investimento do Estado no mercado para assegurar as condições necessárias à industrialização deveria ser seguido pelo investimento na formação de uma nova força de trabalho.
}

\begin{tabular}{|l|l|l|l|l|}
\hline Qevista 2 ialectus & Ano 1 & n. 1 & Julho-Dezembro 2012 & p. 87-100 \\
\hline
\end{tabular}


processo de formação de uma espiritualidade operária submissa aos imperativos de comando do capital. Essa duplicidade também pode se manifestar, no processo de constituição da universidade brasileira, como expressão de um embate entre classes sociais distintas. Escreve Minto:

\begin{abstract}
Pressionada pelo imperialismo, de um lado, e pelas forças sociais nacionalistas, de outro, adquiriu uma fisionomia particular. Os conflitos de classes sobre os quais se constituiu a universidade colocavam em lados opostos projetos de sociedade também opostos. Como as bases estruturais dessa formação social não se alteraram radicalmente, o tipo de instituição que predominou foi aquele capaz de se adaptar às novas necessidades criadas pela institucionalização de uma nova fase do MPC [Modo de Produção Capitalista] no Brasil. Isso fez com que a marginalização de certos projetos de universidade se tornasse uma necessidade histórica neste contexto, não sendo mera expressão do 'atraso' de nossas elites (2011, p. 132).
\end{abstract}

A história da universidade pública é marcada pelo antagonismo entre as classes fundamentais do modo de produção, no entanto, toda a luta desenvolvida pelos defensores da gratuidade do ensino e do caráter laico da educação (escolanovistas e comunistas) não altera em nada a predominância dos interesses do capital perante o trabalho. A universidade emerge como uma necessidade de aprimoramento da subjetividade burguesa, que episodicamente podia ser estendida aos filhos da classe trabalhadora, para assim constituir-se como peça fundamental da difusão do ideário da mobilidade social. No entanto, aqueles que não possuíam as disposições mais ilustres ou as qualidades fundamentais para ingressar na universidade poderiam ser contemplados, mediante processo seletivo, no sistema politécnico de ensino oferecido pelas escolas técnicas em processo de implementação pelo Estado Novo ou no sistema S (Senai, Sesc, Sesi e Senac). Na realidade, o máximo que os filhos do proletariado podiam alcançar era a formação oferecida pelo sistema técnico de ensino. O acesso ao ensino universitário, especialmente em cursos como Medicina e Direito, tem caráter fortuitamente episódico.

A formação tecnicista não se limitava ao desenvolvimento de habilidades técnicas e objetivas, mas servia também para a disseminação dos preceitos axiológicos fundamentais à subordinação da força de trabalho aos imperativos do capital, pois a intensificação da produção pressupunha um sistema eficiente de internalização de regras. É preciso sempre considerar que as determinações gerais do capital não interferem somente na constituição da plataforma da educação formal, mas reverbera por todos os poros da sociedade. Assinala Mészáros:

Enquanto a internalização conseguir fazer o seu trabalho, assegurando os parâmetros reprodutivos gerais do sistema do capital, a brutalidade e a violência podem ser relegadas a um segundo plano [...] visto que são

\begin{tabular}{|l|l|l|l|l|}
\hline Qevista Dialectus & Ano 1 & n. 1 & Julho-Dezembro 2012 & p. 87-100 \\
\hline
\end{tabular}


modalidades dispendiosas de imposição de valores, como de fato aconteceu no decurso do desenvolvimento capitalista moderno (2007, p. 206).

Embora a indústria automobilística chegue ao país somente na década de $50 \mathrm{com}$ Juscelino Kubitschek (1956-1961), é possível assinalar que o desenvolvimento dos pressupostos para uma formação abrangente da classe operária, segundo os imperativos do mercado, foi estabelecido pelo Estado Novo (1937-1945), que soube perfeitamente articular os princípios de dominação de classe através da repressão institucionalizada e da recorrência aos recursos de cooptação das principais lideranças dos movimentos sociais e sindicais. O Estado passou a reger a existência do movimento sindical no estilo do fascismo italiano, interferência que jamais foi suspensa na história do movimento sindical brasileiro.

O golpe de Estado de 1964 vai representar o coroamento do modelo de educação subordinada aos imperativos de uma economia subordinada às determinações de comando do imperialismo norte-americano ${ }^{5}$. A crise estrutural do capital em 1973, em que se configura o colapso dos modelos taylorista e fordista ${ }^{6}$, será plenamente sentida na universidade brasileira no decorrer das décadas seguintes, encontrando seu coroamento na década de 90 e no começo do século XXI, quando a educação superior, finalmente, adequou-se aos imperativos da reestruturação produtiva ou da "precarização flexível". Se não fosse a resistência do movimento estudantil e do movimento docente, a reestruturação da universidade pública, segundo os preceitos do Banco Mundial e do FMI, teria sido realizada imediatamente através dum único decreto governamental. No entanto, o capital impôs, na época do governo FHC, a contenção dos gastos públicos e o corte de verbas para a universidade, aprovando medidas draconianas como a primeira contrarreforma da previdência social (1998), que conduziu vários docentes ao processo de antecipação de suas aposentarias para não perder direitos adquiridos.

A crise da universidade pública se intensifica no contexto de crise estrutural do capital, pois a ofensiva capitalista para expropriar a mais-valia do trabalhador ganha tamanha ubiqüidade que não basta apenas o processo de expropriação do tempo de

\footnotetext{
${ }^{5}$ Segundo Minto (2011, p. 145-146): “A burguesia brasileira precisava, nos anos finais do chamado período 'nacional-desenvolvimentista', sufocar toda e qualquer forma de pressão social, fosse advinda de setores burgueses (e pequeno-burgueses) mais radicais, democráticos ou nacionalistas, fosse das camadas populares. A manutenção da ordem burguesa dependente e subordinada aos ditames do imperialismo tornava-se tão mais imperativa à medida que as forças sociais que a pressionavam ganhavam força. $\mathrm{O}$ Golpe de 1964 foi o resultado disso: o encerramento das possibilidades de desenvolvimento capitalista autônomo, ensaiadas e expressas por certas frações da burguesia brasileira e pelas camadas populares"

${ }^{6} \mathrm{O}$ fordismo representou um aperfeiçoamento da divisão social quando conseguiu submeter o movimento produtivo do trabalhador ao ritmo padronizado e uniformizado da máquina, em que a introdução da linha de montagem representa uma economia acentuada de tempo para o capitalista (Cf. PINTO, 2010).
} 
trabalho decorrido no interior da fábrica, já que é necessário estender sua expropriação às diferentes esferas da vida dos indivíduos, particularmente à educação. A crise estrutural do capital impõe a necessidade de transformação da educação numa mercadoria como outra qualquer. Assim, o que antes era direito da classe trabalhadora resultante da época histórica em que o capital podia fazer, através do Estado, concessões à classe trabalhadora - é superado pela perspectiva da educação como privilégio. A contrarreforma da universidade pública tem como epicentro a noção de que a educação pública deixou de ser um direito da sociedade para constituir-se numa mercadoria fundamental ao processo de reprodução e expansão do capital.

Ao lado do desmonte da universidade pública, mediante contrarreformas em migalhas estatuídas pelo governo Lula (Reuni, Prouni, Ead, Lei de Inovação Tecnológica, Sinaes etc. $)^{7}$, é preciso destacar que a universidade pública vive uma crise que é expressão da crise estrutural que perpassa o capital. Assim, a universidade para o mercado de trabalho se constitui numa mera falácia, porque o mercado nada tem a oferecer à humanidade em sua etapa histórica de crise profunda, senão desemprego, guerra, violência etc.

O desemprego se configura como uma questão inerente ao modo de ser do capital. Isso implica que a formação voltada para o mercado de trabalho não é mais que uma ilusão, pois desconsidera o grave quadro de crescimento das taxas de desemprego em todo o mundo. A ubiquidade do desemprego leva os próprios apologistas do capital a confessar que esse problema realmente veio para ficar (MÉSZÁROS, 2006). No entanto, o processo de formação universitário simplesmente desconsidera o desemprego estrutural e tenta inocuamente difundir a ideologia de que o processo de capacitação da

\footnotetext{
${ }^{7} \mathrm{O}$ governo Lula implementou as contrarreformas no âmbito da educação, segundo o receituário do Banco Mundial e do FMI, de maneira homeopática, quer dizer, fatiando o processo de privatização. $\mathrm{O}$ caráter neoliberal desse governo denominado de "esquerda" se manifesta na cronologia dos decretos aprovados. Foram eles: a) novembro de 2003: Projeto de lei que regulamenta a parceria entre o setor público e o setor privado (PPP); b) abril de 2004: Lei 19.861, que cria os Sinaes; c) setembro de 2004: Decreto 5.205, que regulamenta as fundações privadas ditas de apoio público, legitimando sua presença no interior das universidades; d) dezembro de 2004: Lei 10.973 (Lei de Inovação Tecnológica), que permite a abertura das instalações e laboratórios das universidades públicas para o setor privado, regulamenta a pesquisa a partir dos critérios do mercado, em que o pesquisador passa à condição de empreendedor e participante dos lucros aferidos pelos inventos patenteados, estabelece a separação entre pesquisa, ensino e extensão, pois permite que o pesquisador se afaste de suas atividades de sala de aula para servir à iniciativa privada; e) janeiro de 2005: lei que institui o Prouni, espécie de Proer das instituições privadas de ensino superior que têm $50 \%$ de suas vagas ociosas; f) dezembro de 2005 : Decreto 5.622, que regulamenta o Ensino a distância (Ead) através de fundações privadas e do Banco do Brasil; g) junho de 2006: PL 7.200/06, projeto que institui a reforma universitária; h) abril de 2007: aprovação do Reuni, plano de reestruturação da universidade pública brasileira que prevê a duplicação do número de vagas e a ampliação da relação professor-aluno de 12 para 18, bem como a elevação da taxa de conclusão das graduações e o combate à evasão escolar.
}

\begin{tabular}{|c|c|c|c|c|}
\hline Qevista Dialectus & Ano 1 & n. 1 & Julho-Dezembro 2012 & p. $87-100$ \\
\hline
\end{tabular}


mão de obra permanece como uma das premissas fundamentais para a inserção no mundo do trabalho. Escreve Lerher:

\begin{abstract}
Em um contexto de terrível desemprego, notadamente entre jovens, e de impossibilidade [...] de políticas que permitam a reversão desse quadro, a transformação das instituições de ensino em depositárias das esperanças de inserção social de vastos setores da juventude é - e tem sido - largamente utilizada pelos governos neoliberais como um importante instrumento de governabilidade (2010, p. 3).
\end{abstract}

Apesar do crescente aumento do número de matriculas nas instituições de ensino superior, as taxas de desemprego entre os jovens não diminuíram na última década; pelo contrário, elas crescem de forma cada vez mais acentuada. Segundo o Instituto Nacional de Estatística, o número de jovens desempregados no final de 2011 chegou à taxa de 35,4\%. O desemprego crônico tem conduzido muitos jovens ao beco sem saída da criminalidade. Os dados apontam que os jovens, entre 18 e 29 anos, constituem $56 \%$ da população carcerária nacional (473.626 em 2009, contra 361.102 em 2004 - a população carcerária cresce a uma média de $10 \%$ ao ano $)^{8}$ e que os jovens de 15-24 anos são majoritários na violência homicida, que vitimou mais de 1 milhão de pessoas nos últimos 30 anos no Brasil (WAISELFISZ, 2011). Em vez de adotar medidas substanciais, o governo federal, entre 2008-2010, preferiu ampliar ainda mais o volume de recursos em segurança pública, que passou de 6,92 bilhões para 9,56 bilhões (Fonte: Siga Brasil e Senado Federal/abril de 2011), o que representa um crescimento de quase $40 \%$, ou seja, o equivalente ao volume de recursos destinados às IFES ( 8 bilhões).

A impossibilidade de reformar o capital e resolver o problema do desemprego crônico tem sido sistematicamente confirmada pelas inócuas iniciativas da socialdemocracia, que fracassou em todo o mundo no decorrer do século XX. O capital não pode abrir mão do processo de expropriação do tempo de trabalho, pois capital é acumulação de mais-valia (MARX, 1985). Ele somente pode absorver uma parte da mão de obra disponível da sociedade e lançar outra parte à condição de subemprego ou desemprego. O desemprego faz parte da razão de ser do capital, porque por meio do desemprego ele pode controlar a força de trabalho e impor regras coercitivas de exploração da força de trabalho.

\footnotetext{
8 “O número é quase dez vezes maior do que o crescimento da população total, que vem sendo de $1,4 \%$ ao ano. Por causa disto, o Brasil já é o país com a quarta maior quantidade de pessoas presas no mundo, atrás de Estados Unidos, China e Rússia”. (fonte: http://www.brasil.agenciapulsar.org/nota.php?id=5785). O aumento extraordinário da população carcerária está relacionado às políticas de ajuste impostas pelo FMI e pelo Banco Mundial. Segundo dados do Departamento Penitenciário Nacional, entre 1995 e 2005 , a população carcerária registrou um aumento de 143,91\% (http://www.fatoexpresso.com.br/2010/12/02/prisoes-brasil-tem-terceira-maior-populacao-carceraria-domundo).
}

\begin{tabular}{|l|l|l|l|l|}
\hline Qevista Dialectus & Ano 1 & n. 1 & Julho-Dezembro 2012 & p. 87-100 \\
\hline
\end{tabular}


O processo de reestruturação flexível ${ }^{9}$ do trabalho, pela mediação do modelo toyotista $^{10}$, implica que o ensino especializado da universidade, segundo o modelo taylorista e fordista, perdeu sua razão de ser, pois o trabalhador deve exercer vários ofícios ao mesmo tempo, ou seja, deve converter-se num ente polivalente e multifuncional. O operário polivalente do novo modelo produtivo não implica nenhuma melhoria da qualificação do trabalhador. Como afirma Ohno (1997, p. 42): "Eu sempre disse que deveria levar apenas três dias para treinar novos operários nos procedimentos adequados de trabalho". A polivalência das atividades articula-se ao processo de promoção da "desespecialização" e da "desprofissionalização" dos trabalhadores.

O trabalho rotinizado é a essência do trabalho polivalente; o seu desenvolvimento deve ocorrer por meio do estabelecimento duma sequência de operações que não passam de funções auxiliares do sistema de máquinas. As atividades automatizadas e ritmadas dos operários devem envolver tanto o trabalho individual quanto o trabalho coletivo, pois não basta produzir em larga escala nos ritmos previamente estabelecidos, mas se deve produzir no ritmo uníssono das equipes esportivas, em que os operários são partícipes de um grupo que desenvolve movimentos sincronizados. Os passos articulados da equipe impulsionam os resultados positivos da produção de tal forma que alguns podem ser retirados do processo sem que sua cadência produtiva seja afetada. Afinal, o núcleo fundamental do modelo em questão é a economia de mão de obra para o capitalista, ou seja, ele representa o aprofundamento da demissão de trabalhadores e a manifestação cabal do desemprego como o modo de ser do capital.

Indubitavelmente, a novidade do toyotismo consiste em ter aprofundado o processo de apropriação do tempo de trabalho gratuito que o operário oferece ao capitalista através da destruição da relação paritária existente entre um operário e uma

\footnotetext{
${ }^{9}$ A flexibilização produtiva possibilita que os capitalistas exerçam processos de controle do trabalho graças ao aumento do desemprego nas economias avançadas. Escreve Harvey: "A acumulação flexível implica níveis relativamente altos de desemprego 'estrutural' [...], rápida destruição e reconstrução de habilidades, ganhos modestos (quando há) de salários reais [...] e o retrocesso do poder sindical" (2010, p. 141). Ocorre uma significativa redução do emprego regular em detrimento do trabalho temporário e subcontratado.

${ }^{10} \mathrm{O}$ sistema toyotista caracteriza-se pela profunda reestruturação do tempo de trabalho, pela metodologia da produção e entrega rápida e pela difusão de elementos compatíveis com a empresa "enxuta" e "flexível". No decorrer da metade da década de sessenta, o fordismo começou a demonstrar suas debilidades, à medida que as economias da Europa e do Japão iniciaram o processo de recuperação de suas bases industriais afetadas pela guerra. O processo de deslocamento das multinacionais para o mundo asiático, especialmente o Sudeste, articulado às políticas de substituições de importações para a América Latina, onde o valor da mão de obra era mais baixo, levou à constituição de ambientes novos de concorrência, em que "o contrato social com o trabalho era fracamente respeitado ou inexistia" (HARVEY, 2010, p. 135).
}

\begin{tabular}{|l|l|l|l|l|}
\hline Qevista Dialectus & Ano 1 & n. 1 & Julho-Dezembro 2012 & p. 87-100 \\
\hline
\end{tabular}


máquina, típica do modelo fordista. Essa é chave para preservar os lucros dos capitalistas em tempos de desaquecimento da economia mundial, quando os mercados passam a se retrair cada vez mais e a crise do sistema tende a aprofundar-se cada vez mais, porque as demissões permanentes dos trabalhadores e a redução constante do poder de compra dos trabalhadores resultam na intensificação da redução da capacidade de consumo das massas.

A institucionalização da venda de diplomas através dos cursos aligeirados como o Ead representa a possibilidade da formação plural que interessa ao mercado e resulta na "possibilidade" de um indivíduo portador de vários diplomas exercer várias profissões ao mesmo tempo. A aplicabilidade dessas modalidades de ensino, juntamente com o Prouni e o Reuni, significa que a educação superior adotou um processo de mercantilização irreversível. A última coisa que precisa o trabalhador da reestruturação produtiva é qualificação. Esta não passa duma isca para atrair os jovens desempregados ao reino encantado das universidades privadas. Na verdade, o interesse que está em jogo é somente o interesse de reprodução do capital, que encontrou na educação uma estratégia pertinente para se expandir numa etapa histórica de crise de expansão e acumulação.

É por isso que Mészáros (2006) chama atenção para a necessidade de uma ofensiva socialista contra o capital, pois o quadro de crise estrutural do capital indica que a humanidade somente poderá promover uma alteração substancial da educação mediante a superação da divisão social do trabalho existente. É preciso que a educação se contraponha à perspectiva da relação de troca de mercadorias para se colocar na perspectiva de troca de atividades (MÉSZÁROS, 2006). Nesse aspecto, a universalização do trabalho se constitui como elemento fundamental.

O sistema do capital, complexo e multiforme, mostra-se sempre capaz de se metamorfosear para garantir a manutenção da ordem estabelecida e inseri-se nas camadas mais profundas da existência dos indivíduos. É fundamental entender que a ofensiva socialista deve partir do princípio de que a educação envolve a totalidade da existência dos indivíduos e não se limita a um determinado período de suas existências. A educação socialista deve se colocar frontalmente contra a educação fundada no processo de doutrinação para o mercado. Ela deve lançar abaixo a divisão social do trabalho que fundamenta o modo de produção capitalista, pois todo processo de formação profissional tem como propósito fundamental a economia de tempo segundo os imperativos inquestionáveis do mercado. É preciso libertar o trabalho do

\begin{tabular}{|l|l|l|l|l|}
\hline Qevista Dialectus & Ano 1 & n. 1 & Julho-Dezembro 2012 & p. 87-100 \\
\hline
\end{tabular}


confinamento desumano das funções especializadas que impede os trabalhadores de exercer as suas funções criativas e autoprodutivas.

A educação deve ser projetada na perspectiva de uma nova formatação da divisão social do trabalho, já que o sistema que estrutura o processo de educação na universidade está profundamente conectado ao mercado e tem como meta alijar os trabalhadores de quaisquer funções decisivas no sistema de controle e comando de suas próprias atividades (MÉSZÁROS, 2007). Deve-se entender que a "universidade" e a fábrica capitalista não são entidades isoladas, mas partes substantivas de uma totalidade profundamente conectada, e que, enquanto existir o capital, essas instituições serão moldadas pelos seus imperativos de controle e submissão.

Uma perspectiva socialista de educação deve demolir inteiramente o edifício de subsunção do sistema de valores do capital, que representa um processo de internalização de mecanismos sofisticados de aceitação absoluta da divisão social do trabalho e da formação na perspectiva de produção de mercadoria (valor de troca). Trata-se de constituir uma nova forma de objetividade que esteja a serviço de toda a humanidade. Ante a hegemonia dos processos de internalização postos pelo capital, é preciso constituir “uma atividade de 'contrainternalização', coerente e sustentada, que não se esgote na negação [...] e que defina seus objetivos fundamentais, como a criação de uma alternativa abrangente concretamente sustentável ao que já existe" (MÉSZÁROS, 2007, p. 212). Para isso é imprescindível alterar todo o processo de produção fundado na disjunção entre trabalho manual e trabalho intelectual, em que este comparece como instrumento de dominação do capital sobre o trabalho. A educação deve colaborar na constituição de preceitos axiológicos capazes de interceptar a divisão social do trabalho que perpassa o modo de produção capitalista, pois a lógica da produção de mercadorias embotam a capacidade criativa do ser humano e sua possibilidade de realizar-se como ser omnilateral.

\section{Referências bibliográficas}

FATO EXPRESSÃO. Prisões: Brasil tem terceira maior população carcerária do mundo. Disponível em: <http://www.fatoexpresso.com.br>. Acesso em $1^{\circ}$ de jun. 2012.

HARVEY, D. Condição pós-moderna: uma pesquisa sobre as origens da mudança cultural. 19a edição. Trad. Adail Ubirajara Sobral e Maria Stela Gonçalves. São Paulo: Loyola, 2010.

\begin{tabular}{|l|l|l|l|l|}
\hline Qevista Dialectus & Ano 1 & n. 1 & Julho-Dezembro 2012 & p. 87-100 \\
\hline
\end{tabular}


LEHER, Roberto. O governo Dilma, a greve nacional dos docentes e a universidade de serviços. Rio de Janeiro: 2012.

A contrarreforma universitária de Lula da Silva. Endereço eletrônico: http://www.barricadasabremcaminhos.files.wordpress.com/2010/06/leher-re. Acesso em 27 de abril de 2012.

LUKÁCS, G. Introdução aos escritos estéticos de Marx e Engels. Trad. Leandro Konder. In. LUKÁCS, G. Ensaios de literatura. Rio de Janeiro: Civilização Brasileira, 1965.

A reprodução. Trad. Sérgio Lessa. Texto mimeografado. Extraído de Per

l'ontologia dell'essere sociale. Vol. II. Roma: Editori Riuniti, 1981.

MARX, K. O capital: crítica da economia política. Livro primeiro. Vol. I. Trad. Regis Barbosa e Flávio R. Kothe. São Paulo, Nova Cultural, 1985.

MARX, K - ENGELS, F. A ideologia alemã. Trad. José Carlos Bruni e Marco Aurélio Nogueira. São Paulo: Hucitec, 1987.

MESZÁROS, I. Para além do capital: rumo a uma teoria da transição. Trad. Paulo Cezar Castanheira e Sérgio Lessa. São Paulo: Boitempo, 2006.

O desafio e o fardo do tempo histórico: o socialismo no século XXI. Trad. Ana Cotrim e Vera Cotrim. São Paulo: Boitempo, 2007.

Estrutura social e formas de consciência II: a dialética da estrutura e da história. Trad. Rogério Bettoni. São Paulo: Boitempo, 2011.

Paulo: Boitempo, 2008.

Filosofia, ideologia e ciência social. Trad. Ester Vaisman. São

MINTO, Lalo Watanabe. A educação da "miséria": particularidade capitalista e educação superior no Brasil. Campinas, SP: Tese de doutorado/Unicamp, 2011.

PINTO, Geraldo Augusto. A organização do trabalho no século XX: taylorismo, fordismo e toyotismo. $2^{\mathrm{a}}$ edição. São Paulo: Expressão, 2010.

PULSAR BRASIL. População carcerária cresce $10 \%$ ao ano no Brasil. Disponível em: <http://www.brasil.agenciapulsar.org/nota $>$. Acesso em 23 abr. 2012.

OHNO, Taiichi. O sistema toyota de produção: além da produção em larga escala. Trad. Cristina Shumacher. Porto Alegre: Bookman, 1987.

WAISELFISZ, Julio Jacobo. Mapa da violência 2012: os novos padrões da violência homicida no Brasil. São Paulo: Instituto Sangrai, 2011.

\begin{tabular}{|l|l|l|l|l|}
\hline Qevista Dialectus & Ano 1 & n. 1 & Julho-Dezembro 2012 & p. 87-100 \\
\hline
\end{tabular}

